\title{
AFTERSHOCK SEQUENCES RECORDED DURING A MICROEARTHQUAKE OBSERVATION AT KAMIKINEUSU, HOKKAIDO (1964-1972)
}

\author{
Yoshinobu Motoya \\ Sapporo Seismological Observatory, Faculty of Science, \\ Hokkaido University, Sapporo, Japan \\ (Received February 4, 1974; Revised July 20, 1974)
}

\begin{abstract}
Using the data obtained at the Urakawa Seismological Observatory (KMU), the seismicity in and near Hokkaido was investigated for the period from May 1964 through December 1972. An aftereffect of the 1968 Tokachioki earthquake of magnitude 7.9 has been recognized up to date, the end of 1972. Some features of aftershock and foreshock sequences detected at KMU are described. Aftershock activity differs considerably from place to place in the region concerned, but it shows no systematic trends. The phenomenon of secondary aftershocks is not rare. Considering the relation of the number of aftershocks to the magnitude of a triggering earthquake, the secondary aftershock activity is comparable to the primary aftershock activity in most cases.
\end{abstract}

\section{Introduction}

From May 1964 to November 1966, a highly sensitive seismic observation was continued at Kamikineusu, Urakawa, southern Hokkaido. The purpose of this observation was to investigate the regional microseismicity and related problems (Mотоy et al., 1965; Motoya, 1967). In 1966, the Urakawa Seismological Observatory, Hokkaido University was established under the Earthquake Prediction Research Project of Japan. It is located at nearly the same site as that of the temporary observation mentioned above. The station code is KMU. The routine seismic observation was started on July 1, 1967 and the data have been published in the form of station bulletins. In this paper an aspect of the seismicity around Hokkaido and a study of some aftershock sequences recorded in these observations are described.

\section{Observation}

Pre-KMU observation

Our temporary station was equipped by a $1.0 \mathrm{~Hz}$ vertical component seismometer operated at 0.7 critical damping. The seismometer was installed 
about $250 \mathrm{~m}$ south of the present KMU seismometer pier. Seismometer signals are amplified and recorded on a smoked paper by a scratch-recording galvanometer with $30 \mathrm{~Hz}$ natural frequency. The overall response is constant in the frequency range between 1.5 and $25 \mathrm{~Hz}$ and the velocity sensitivity was adjusted to a level between 80 and $120 \mu \mathrm{kine} / \mathrm{mm}$ according to the conditions of background noise. This temporary observation is called the pre-KMU observation in this paper.

\section{Observation of the Urakawa Seismological Observatory}

The observation of KMU has been continued with two vertical and two horizontal seismometers installed on the cretaceous fine sandstone. The station coordinates are $42^{\circ} 14^{\prime} 19^{\prime \prime} \mathrm{N}$ latitude and $142^{\circ} 58^{\prime} 02^{\prime \prime} \mathrm{E}$ longitude. The elevation is $185 \mathrm{~m}$ above the sea level. The recording system uses $35 \mathrm{~mm}$ photofilm. The natural frequency of the seismometer is $1.0 \mathrm{~Hz}$ and that of the galvanometer is about $3 \mathrm{~Hz}$.

\section{Data and Magnitude Determination}

In the pre-KMU observation all earthquakes recorded were investigated. Almost all earthquakes with maximum velocity amplitude over $100 \mu \mathrm{kine}$ could not escape from investigation during the whole observation period. Under the assumption of a sinusoidal wave, the relation between displacement amplitude $A$ and velocity amplitude $V$ is expressed as

$$
A=\left(\frac{T}{2 \pi}\right) \cdot V
$$

where $T$ is the wave period. From this relation, a velocity amplitude of 100 $\mu$ kine corresponds to a displacement amplitude between 15 and $45 \mathrm{~m} \mu$, as the seismic wave period actually ranges from 3 to $10 \mathrm{~Hz}$ in most cases.

In the routine observation of $\mathrm{KMU}$, only earthquakes for which the maximum trace amplitude on the low magnification vertical component ( $Z$ in Fig. 1) exceeds $0.5 \mathrm{~mm}$ have been investigated. This level corresponds to about $30 \mathrm{~m} \mu$ in displacement amplitude.

The data used in this study are supplied mainly from the observations described above. Seismograms of high magnification vertical component $(Z X$ in Fig. 1) are also examined, when necessary. Hypocentral parameters of earthquakes in the Seismological Bulletin of the Japan Meteorological Agency (JMA) are employed. Magnitudes of earthquakes with focal depth larger than $60 \mathrm{~km}$ are not determined by JMA. Magnitudes of earthquakes with focal depth between 60 and $100 \mathrm{~km}$ were calculated in this study from TsuBor's formula (1954). This formula is usually valid for earthquakes shallower than 


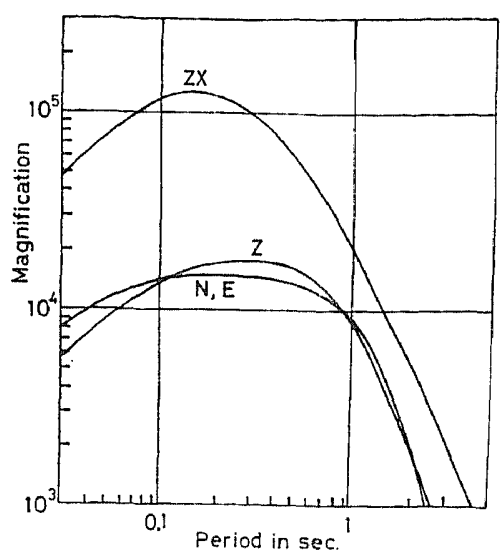

Fig. 1. Magnification curves of seismographs used at the Urakawa Seismological Observatory (KMU).

$60 \mathrm{~km}$. However, the systematic error of magnitude calculated from this formula is estimated to be less than 0.1 unit, if the focal depth is less than 100 $\mathrm{km}$ (KisHio et al., 1972).

An empirical equation has been developed for estimating the magnitude of small earthquakes from the P-S interval and the maximum amplitude recorded at KMU station (MотоYA, 1969). It is expressed by

$$
M=\log A_{z}+1.75 \log \tau+2.14
$$

where $A_{Z}$ is the vertical ground amplitude in microns and $\tau$ is the P-S interval in seconds. Magnitudes of small earthquakes which were not located by JMA were calculated by this equation.

\section{Seismicity in and around Hokkaido}

It is meaningless to compare directly the number of earthquakes observed before 1966 and that after 1967, because the type and sensitivity of the seismometers are different between the two periods. As is remarked above, however, we may investigate earthquakes on almost the same basis if shocks with maximum velocity amplitude over $100 \mu$ kine are taken from the pre-KMU observation.

The number of earthquakes in every ten-day interval is shown in Fig. 2. Lack of column means no observation. Arrows with numerals indicate the occurrences of some remarkable earthquakes and the numerals give their magnitudes. Remarkable earthquakes which occurred in and around northern Japan from May 1964 to December 1972 are listed in Table 1. Up to 1967, the seismicity in the southern Kuril Islands region decreases gradually, which 


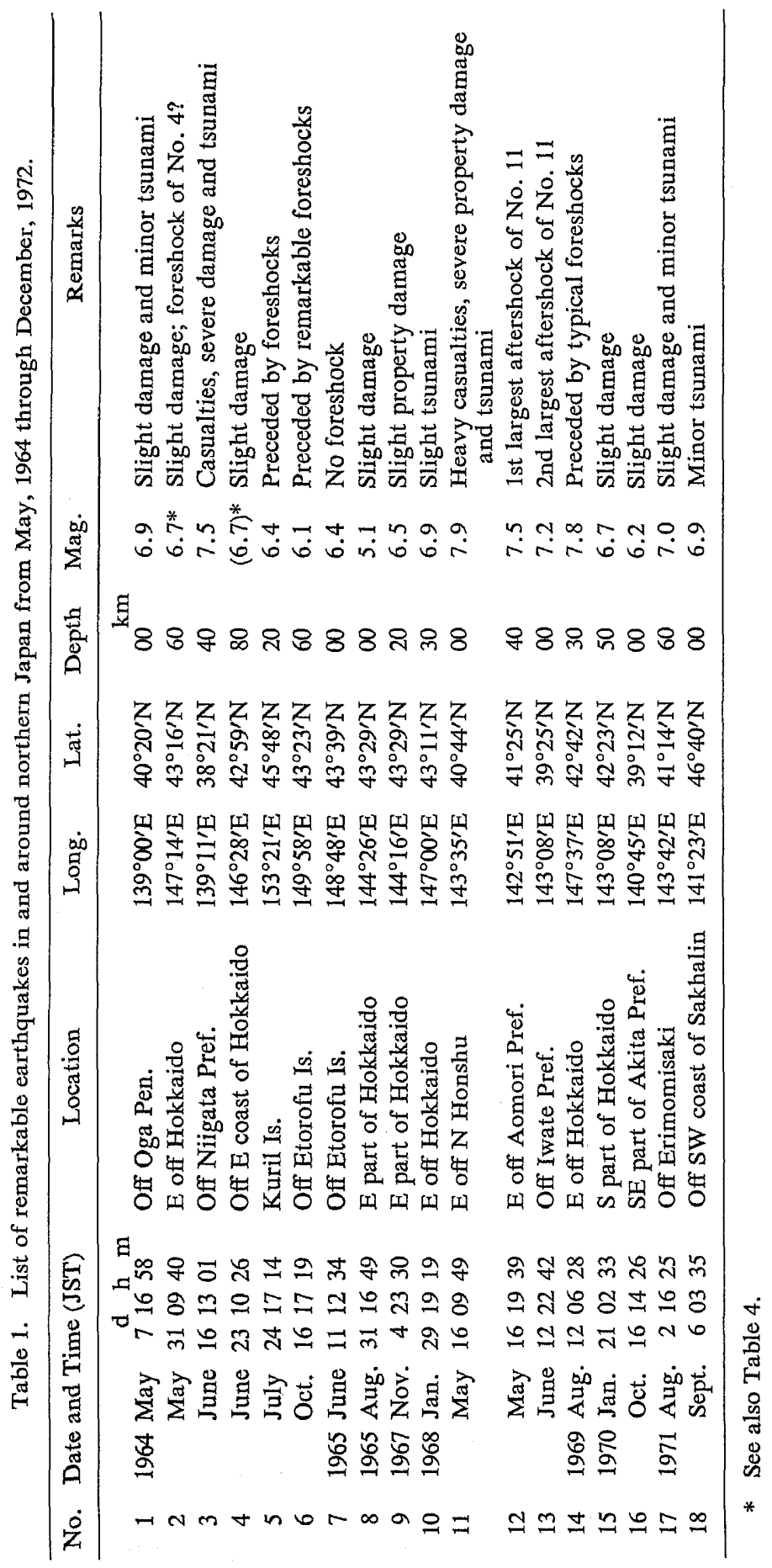




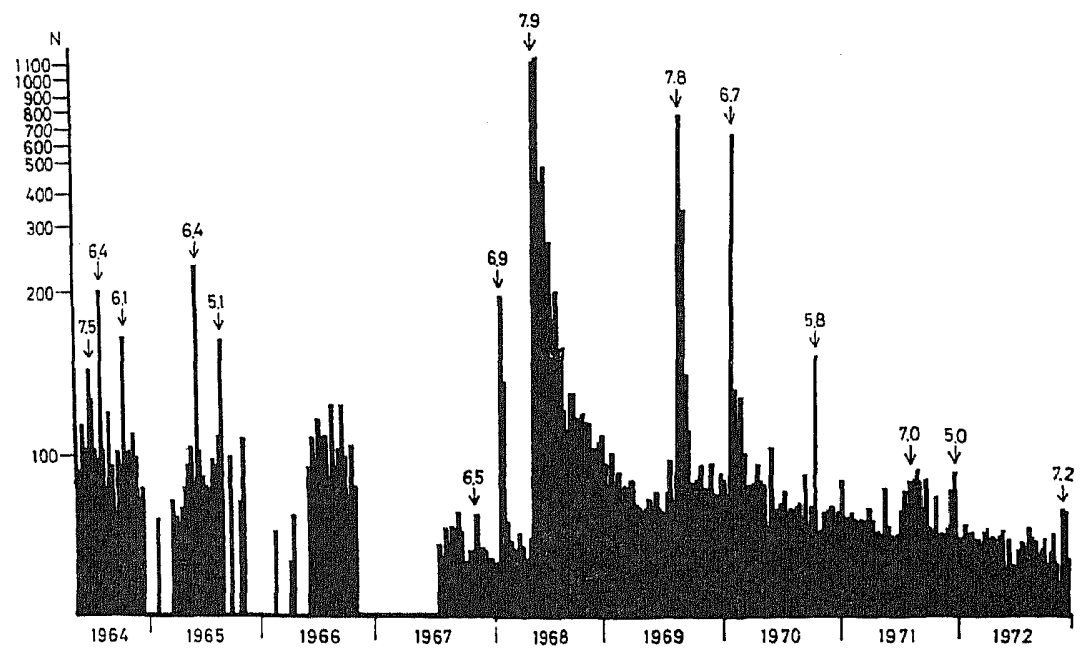

Fig. 2. Number of earthquakes observed at Kamikineusu in every ten-day interval.

is probably related to the aftershock activity of the great earthquake of 1963 $(M=8.1)$ which occurred in this region. From June to October in 1966, the number of small shocks observed at Kamikineusu showed a relative increase without any large earthquake accompanied by many aftershocks.

On May 16, 1968, the 1968 Tokachi-oki earthquake of magnitude 7.9 occurred off the south coast of Hokkaido. Numerous aftershocks followed this earthquake and its aftereffect may be recognized up to date, the end of 1972. Moreover, it is pointed out that the occurrence of this shock activated the seismicity near Urakawa, $150 \mathrm{~km}$ north of its epicenter and out of the aftershock area (МоточA, 1972). Such a large earthquake may have effects upon the seismicity in some separated regions from its source region.

\section{Study on Earthquake Sequences}

In the course of this study, it is necessary to decide whether or not a given shock is accompanied by any foreshocks and aftershocks. As we do not know the physical definition of fore- and aftershock at present, we treat it rather practically as follows. When one or more shocks are observed within one hour intervals immediately before and after a major earthquake and their P-S intervals fall in the range predicted from the location and magnitude of the major shock, we regard that the earthquake is preceded by foreshocks and accompanied by aftershocks respectively.

\subsection{Earthquakes accompanied by aftershocks}

It is interesting to know the lower limit of magnitude of earthquakes 
accompanied by aftershocks. This problem was investigated by UTSU (1961) using the data from JMA. Improvements of instrumentation in recent years have much increased the quality and quantity of aftershock data. It may be expected that if we could observe the very small shocks, almost all earthquakes might be accompanied by aftershocks. In this regard, however, sufficient data have not yet been supplied. Though the data immediately after a main shock are essentially important, this kind of data is hardly obtainable by temporary observations, especially in the case of a small main shock. Our observation supplies a certain amount of such data.

We investigated all available earthquakes (focal depth $\leqq 100 \mathrm{~km}$ ) which occurred within the area shown in Fig. 3 from May 1964 to October 1966 and in Fig. 4 from January 1970 to June 1972. Almost all earthquakes with magnitude over 2 occurring in this area are detected by our observation. Moreover, small earthquakes not located by JMA were investigated from September 1970 to June 1972. These shocks occurred near our station and the minimum magnitude of observable earthquake is 1.5 or less in this case.

With a careful inspection of P-S interval and waveform, all seismograms obtained at Kamikineusu were re-examined. In most cases aftershocks were easily distinguishable at a glance of seismogram. Results are represented in Table 2 and Figs. 3 and 4 . From this table it is found that earthquake of magnitude larger than 6 is always accompanied by aftershocks. As the magnitude goes down from 6 , the percentage of earthquakes accompanied by

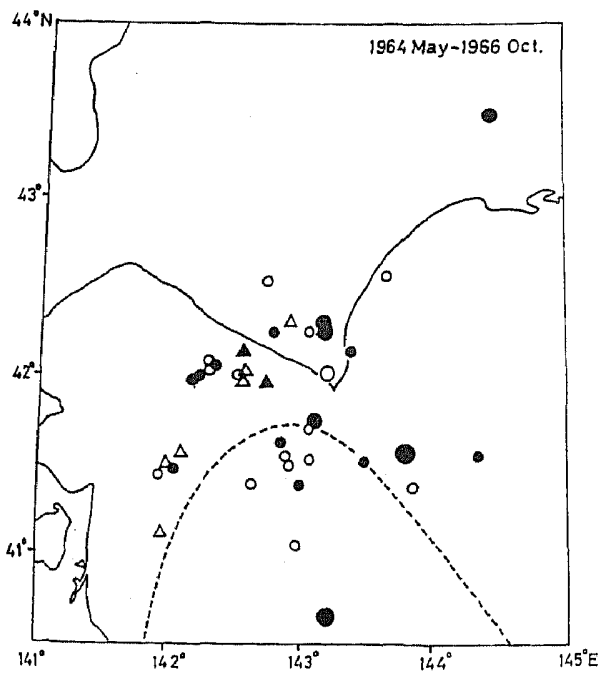

Fig. 3.

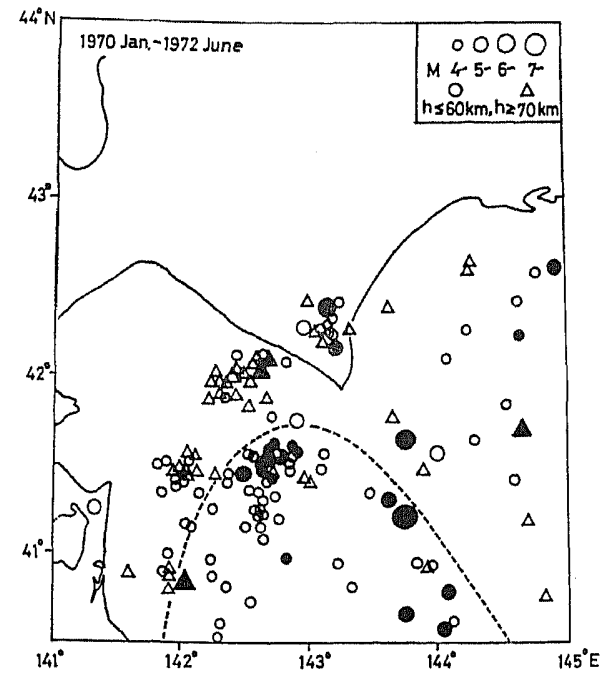

Fig. 4.

Figs. 3 and 4. Epicenters of earthquakes investigated (after JMA). Solid symbols represent earthquakes accompanied by observable aftershocks. 
Table 2. Percentage of earthquakes accompanied by aftershocks.

\begin{tabular}{|c|c|c|c|c|c|c|c|c|c|}
\hline \multirow{3}{*}{ Magnitude } & \multicolumn{6}{|c|}{ Vicinity of Urakawa } & \multirow{2}{*}{\multicolumn{3}{|c|}{$\begin{array}{c}\begin{array}{c}\text { Vicinity of Kyoto } \\
\text { (OKANO, 1970) }\end{array} \\
\text { very shallow }\end{array}$}} \\
\hline & \multicolumn{3}{|c|}{$h \leqq 60 \mathrm{~km}$} & \multicolumn{3}{|c|}{$70 \leqq h \leqq 100 \mathrm{~km}$} & & & \\
\hline & $N$ & $A$ & $A / N$ & $N$ & $A$ & $A / N$ & $N$ & $A$ & $A / N$ \\
\hline $2.0-2.9$ & (200) & 4 & & & & & & & \\
\hline $3.0-3.9$ & $(60)$ & 5 & & & & & 37 & 11 & $32.4 \%$ \\
\hline $4.0-4.4$ & 72 & 14 & $19.4 \%$ & 29 & 1 & $3.4 \%$ & 5 & 5 & 100.0 \\
\hline $4.5-4.9$ & 27 & 8 & 29.6 & 16 & 1 & 6.2 & 6 & 6 & 100.0 \\
\hline $5.0-5.9$ & 18 & 9 & 50.0 & 4 & 3 & 75.0 & 2 & 2 & 100.0 \\
\hline $6.0-6.9$ & 4 & 4 & 100.0 & 1 & 1 & 100.0 & & & \\
\hline $7.0-$ & 1 & 1 & 100.0 & & & & & & \\
\hline
\end{tabular}

$N$; number of all earthquakes investigated.

$A$; number of earthquakes accompanied by observable aftershocks.

aftershocks decreases gradually. The decrease in aftershock activity with increasing focal depth has been pointed out (MogI, 1963). Low percentage may be seen in the depth range of 70 to $100 \mathrm{~km}$ in our region.

OKANO (1970) investigated aftershock activity in the vicinity of Kyoto. From the table in his paper, aftershock sequences in which the largest aftershock had magnitude larger than 2.0 were selected out. The number of all earthquakes investigated by him and that of earthquakes accompanied by the aftershock sequences selected are also given in Table 2. It is seen that earthquakes in the vicinity of Kyoto are accompanied by aftershocks much more frequently than those in our region. Earthquakes investigated by him have P-S intervals less than $2.5 \mathrm{sec}$. Therefore they occur in the earth's crust. On the other hand, most of earthquakes investigated here are deeper and probably occur in upper most part of the mantle. The seismicity near our station is rather low. From January 1971 to June 1972, only one small earthquake with the P-S interval of $2.5 \mathrm{sec}$ or less is registered on the KMU bulletin. It should be noted that this small shock was obviously accompanied by microaftershocks, though its magnitude was estimated as only 1.9 (MotoyA, 1973).

As shown in Figs. 3 and 4, the spatial distribution of earthquakes accompanied by observable aftershocks does not any systematic pattern. The dotted line indicates a part of the border of the aftershock area of the 1968 Tokachi-oki earthquake according to UTSU (1969). A tendency may be seen that earthquakes accompanied by aftershocks are apt to lie along the rim of this area.

\subsection{Earthquakes preceded by foreshocks}

From the viewpoint of earthquake prediction, it is interesting to find out foreshocks prior to a major earthquake. To our regret, foreshocks are observed 
Table 3. Data on foreshock sequences.

\begin{tabular}{|c|c|c|c|c|c|c|}
\hline Date & $M_{0}$ & $M_{1}$ & $t_{1}$ & $M_{F}$ & $t_{\mathrm{F}}$ & Remarks \\
\hline 1964 July $24,17^{\mathrm{h}} 14^{\mathrm{m}}$ & 6.4 & 6.0 & $\mathrm{~d} \underset{850}{\mathrm{~h}} \mathrm{~m}$ & 5.9 & ${ }_{122}^{\mathrm{h} m}$ & \\
\hline 1964 Oct. 16,1719 & 6.1 & 5.6 & 110 & 5.9 & 118 & \\
\hline 1969 July 29,1739 & 4.0 & 3.5 & 30340 & 3.5 & 22 & only one foreshock \\
\hline 1969 Aug. 12, 0628 & 7.8 & 6.2 & 21651 & & & typical C-type* \\
\hline 1971 July 15,1957 & 4.5 & 2.3 & 4 & 3.9 & 2 & only one foreshock \\
\hline 1971 Aug. 17, 0041 & 5.3 & 4.8 & 91444 & 5.1 & 2 & only one foreshock \\
\hline
\end{tabular}

$M_{0}$; magnitude of the main shock, $M_{1}$; magnitude of the largest aftershock, $t_{1}$; time interval between the main shock and the largest aftershock, $M_{F}$; magnitude of the largest foreshock, $t_{F}$; time interval between the largest foreshock and the main shock.

* According to ISC bulletin, the largest foreshock of magnitude 5.9 (ISC) occurred only 4 seconds before the main shock.

much less frequently than aftershocks. However, some examples were detected in our observation. Earthquake sequences preceded by at least one foreshock within one hour before the main shock are shown in Table 3. It is noticeable that the magnitude of the largest foreshock is nearly equal to or larger than that of the largest aftershock, in spite of the fact that foreshocks are fewer than aftershocks. It may give support to the opinion that the $b$ value for foreshocks is smaller than that for aftershocks (SuYEHrRo et al., 1964).

MOGI (1967 a) mentioned that the time distribution of foreshocks is classified into two types, C-type (gradually increasing activity toward the main shock) and D-type (sudden increase of activity followed by a decrease before the main shock). In a foreshock sequence of D-type, no foreshock may be observed within one hour before the main shock. An example of such foreshock sequences is, as remarked in Table 5, a series of earthquakes accompanying an earthquake of magnitude 5.3 on May 2, 1968 in the region of the 1968 Tokachi-oki earthquake.

\subsection{Study on aftershock sequences}

In regard to most of earthquakes listed in Table 1 , foreshock and aftershock sequences were investigated using the data obtained at Kamikineusu. The results are summarized in Table 4 . In addition to this, some aftershock sequences investigated in this paper are shown in Table 5 with the same notations as in Table 4. The linear dimension of an aftershock region was estimated from the upper and lower limits of P-S distribution of aftershocks observed at Kamikineusu. UTSU (1969) reported a few aftershock sequences having the value of $c$ less than 0.1 day. However, the values of $c$ may be very small in rather many sequences when the data in early stages are included.

On August 2, 1971, a considerably large earthquake (C in Fig. 5) occurred 
Table 4. Summary of the results on aftershock sequences (1).

\begin{tabular}{|c|c|c|c|c|c|c|c|c|c|c|}
\hline No.* & $M_{0}$ & $M_{1}$ & $t_{1}$ & $M_{0}-M_{1}$ & $p$ & $c$ & $b$ & $D 1$ & Mark** & Reference \\
\hline 1 & 6.9 & 6.5 & $\mathrm{~d}_{1215}^{\mathrm{h} m}$ & 0.4 & 1.3 & $0.25^{\mathrm{d}}$ & & & $\mathrm{km}$ & $\begin{array}{l}\text { Nos. } 1 \text { to } 7 \text {, Motoya } \\
\text { (1970 a) }\end{array}$ \\
\hline 2 & $6.64^{* * * *}$ & 5.0 & 11742 & 1.6 & & & $(0.4)$ & & & \\
\hline 3 & 7.5 & 6.1 & 16 & 1.4 & 1.6 & 0.33 & 0.95 & & & \\
\hline 4 & $6.71 * * *$ & 4.0 & 21640 & 2.7 & 1.0 & 0.000 & 0.85 & 42 & & \\
\hline 5 & 6.4 & 6.0 & 850 & 0.4 & 0.8 & 0.000 & 1.11 & & $\mathrm{~S}$ & \\
\hline 6 & 6.1 & 5.6 & 110 & 0.5 & 1.0 & 0.05 & 1.10 & 67 & & \\
\hline 7 & 6.4 & 5.3 & 437 & 1.1 & 1.5 & 0.58 & 1.15 & 59 & & \\
\hline 8 & 5.1 & 5.0 & 15 & 0.1 & 1.3 & 0.042 & 0.85 & 34 & & $\begin{array}{l}\text { HrRota }(1969 \mathrm{~b}) \\
\text { MOTOYA }(1970 \mathrm{a})\end{array}$ \\
\hline 9 & 6.5 & 5.6 & 15 & 0.9 & 1.2 & 0.05 & 1.10 & 68 & & HIROTA (1969b) \\
\hline 10 & 6.9 & 5.8 & 60042 & 1.1 & 1.3 & 0.18 & 0.67 & 153 & s & Hirota (1969a) \\
\hline 11 & 7.9 & 7.5 & 950 & 0.4 & 0.9 & & 0.85 & 280 & $\mathrm{~s}$ & $\begin{array}{l}\text { OKADA and Motoya } \\
(1970)\end{array}$ \\
\hline 14 & 7.8 & 6.2 & 21651 & 1.6 & 1.0 & 0.02 & 0.72 & 180 & $\mathrm{~S}$ & MotoYA (1969b) \\
\hline 15 & 6.7 & 4.8 & 1926 & 1.9 & 1.1 & 0.04 & 0.7 & 26 & & $\begin{array}{l}\text { MoroYA and } \\
\text { KITAGAMAE (1971) }\end{array}$ \\
\hline 17 & 7.0 & 5.8 & 535 & 1.2 & 0.8 & 0.008 & $(0.7)$ & 73 & $\mathrm{~S}$ & this paper \\
\hline
\end{tabular}

$M_{0}$; magnitude of the main shock, $M_{1}$; magnitude of the largest aftershock, $t_{1}$; time interval between the main shock and the largest aftershock, $p$ and $c$; constants in the equation $n(t)=A(t+c)^{-p}, b$; constant in the equation $\log n(M)=a-b M, D$; linear dimension of the aftershock area.

* same as in Table 1,

** see the text,

*** $M_{0}$ is the average of magnitudes from 14 JMA stations in Hokkaido. The shock No. 4 may be slightly larger than No. 2. Other $M_{0}$ are JMA magnitudes.

off Erimo Cape, about $120 \mathrm{~km}$ SSE of KMU station. This shock, termed the Erimomisaki-oki earthquake in this paper, is noticeable in respect to the small number of aftershocks in spite of its large magnitude of 7.0. Since this shock is located at the rim of the aftershock area of the 1968 Tokachi-oki earthquake (A in Fig. 5), we may regard it as one of the aftershocks of this great shock. If so, it is the third largest aftershock. It may be related to the concept that if an earthquake of this magnitude did not occur in an aftershock sequence, it might be followed by many observable aftershocks. However, considering that the largest aftershock ( $B$ in Fig. 5) of magnitude 7.5 and the second largest one of magnitude 7.2 had remarkable series of aftershocks of their own and that even some of aftershocks (for example, D and $E$ in Fig. 5) of magnitude under 7 were obviously accompanied by secondary aftershocks (OKADA and Motoya, 1970), it may be safely said that the Erimomisaki-oki earthquake showed extremely low aftershock activity.

Some features of this unconspicuous aftershock sequence are described. Cumulative frequency of aftershocks observed at KMU is plotted in Fig. 13 


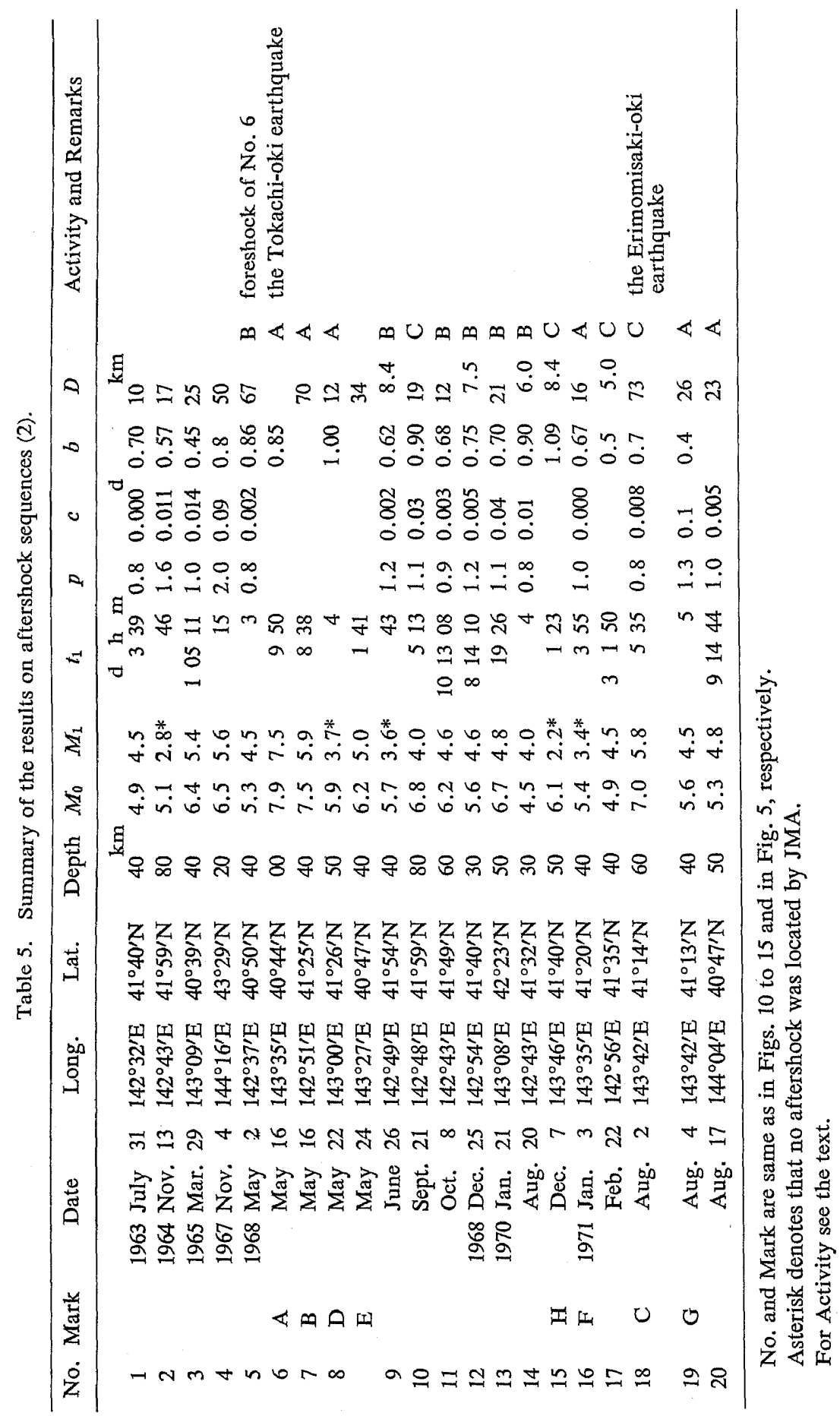




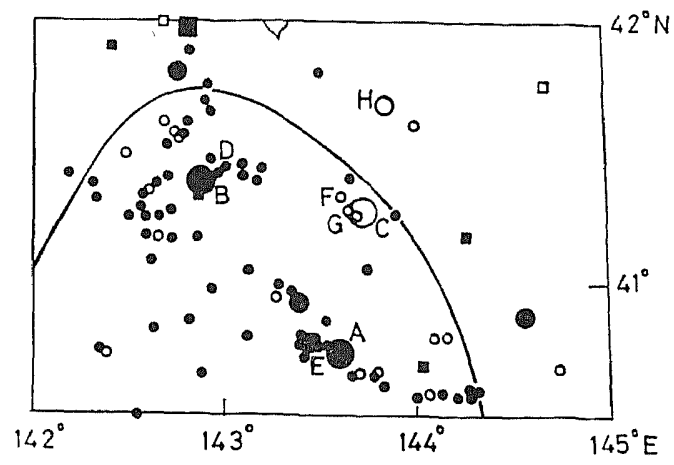

Fig. 5. Epicenters of earthquake (after JMA). Solid and open symbols represent earthquakes in 1967-1969 and those in 1970-1971, respectively. The solid line indicates a part of the border of the aftershock area of the 1968 Tokachi-oki earthquake. For capitals see the text.

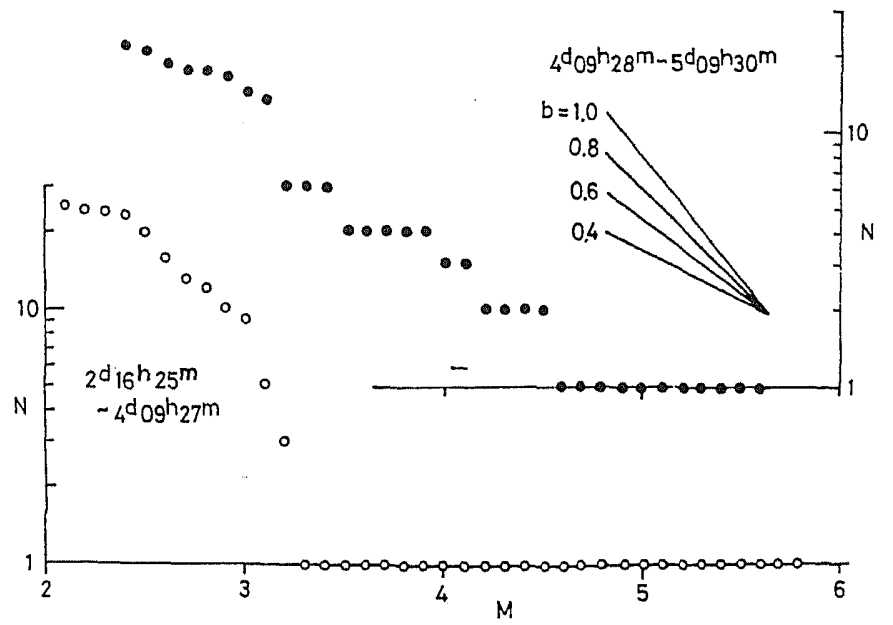

Fig. 6. Magnitude-cumulative frequency relations for the aftershock sequence of the Erimomisaki-oki earthquake on August 2, 1971. Open and solid circles indicate the relation before and after the second largest aftershock, respectively.

against the time from the main shock. The aftershock activity was not at all affected by the occurrence of the largest aftershock of magnitude 5.8. On the other hand, the second largest one ( $G$ in Fig. 5) of magnitude 5.6 was accompanied by many secondary aftershocks. As shown in Fig. 6, a change in magnitude-frequency relations was also found before and after the second largest aftershock; before it the largest aftershock departed extremely from other ones in magnitude, while after it many moderate aftershocks occurred as expected from GUTENBERG-RICHTER's statistical formula. 


\subsection{Aftershock activity}

The aftershock activity of an earthquake has been interpreted differently by various investigators. The difference in magnitude between an earthquake and its largest aftershock $M_{0}-M_{1}$ has been used as a simple measure of the aftershock activity (MOGI, $1967 \mathrm{~b}$ ). It may be reasonable to use the number of aftershocks observed, because not only largest aftershock but also many shocks in the sequence are included. In fact, aftershock activity in the vicinity of Kyoto was successfully indicated by number of aftershocks observed (OKANO, 1970).

It is well known that frequency of aftershocks is expressed by the formula (UTSU, 1961),

$$
n(t)=\frac{A}{(t+c)^{p}}
$$

where $n(t)$ denotes the frequency of aftershocks in a unit time interval at time $t$ measured from the origin time of the main shock, and $c, p$ and $A$ are constants. UTSU (1970) considered the average rate of occurrence of aftershocks having magnitude $M_{s}$ and larger $t$ days after a shallow earthquake of magnitude $M_{0}$. For this purpose the following equation is devised by him to represent a standard rate of occurrence of aftershocks per day,

$$
n(t)=\frac{10^{0.88\left(M K_{0}-M H_{s}\right)-1.83}}{(t+0.3)^{1.3}}
$$

This expression is obtained from equation (3) with the numerical values of $p=1.3, c=0.3$ day and $A=10^{0.85\left(M_{0}-M M_{s}\right)-1.83}$. These values of $p$ and $c$ are the medians for 66 sequences investigated by him.

The cumulative frequency curve of aftershocks, however, is more useful

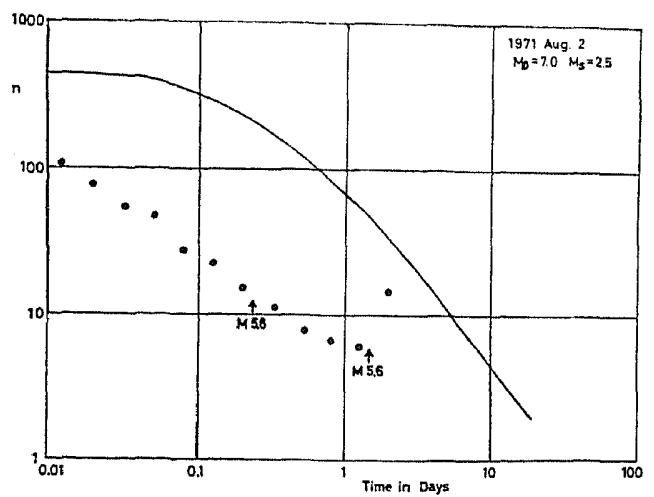

Fig. 7. Low aftershock activity of the Erimomisaki-oki earthquake. Solid line indicates the frequency of aftershocks calculated from equation (4) with values $M_{0}=7.0$ and $M_{8}=2.5$. 
when sufficiently many aftershocks are not available. If the frequency of aftershocks is given by Eq. (3), the cumulative frequency $N(t)$ is expressed as

$$
N(t)=\int_{0}^{t} \frac{A}{(t+c)^{p}} \cdot \mathrm{d} t .
$$

For various values of $c, n(t)$ and $N(t)$ are illustrated in Figs. 8 and 9. Considerable differences in $N(t)$ are noted for various values of $c$, even if rates of occurrence of aftershocks are identical in late stages of the sequences. The total number of aftershocks observed in a relatively short time interval from the main shock must reflect aftershock activity in early stages of the sequence. Of course, it depends on not only parameter $A$ but also $c$.

In Figs. 10 to 15 , the cumulative frequency curves are shown for some aftershock sequences. Using Eq. (4), we can estimate Eq. (5) for these sequences. The calculated value of $N(t)$ is shown by a dotted line, which can be used as a standard of aftershock activity. To give a rough estimate of the degree of aftershock activity, events were grouped into four classifications, $\mathrm{A}, \mathrm{B}, \mathrm{C}$ and $\mathrm{D}$ according to the following criterion. A sequence for which the observed cumulative frequency is always superior to the calculated value of $N(t)$ is labeled A (Fig. 10); a sequence for which the observed frequency coincides roughly with $N(t)$ is labeled B (Fig. 11); a sequence for which the observed frequency is always inferior to $N(t)$ is labeled $\mathrm{C}$ (Fig. 12); an event accompanied by no observable aftershocks is labeled $\mathrm{D}$.

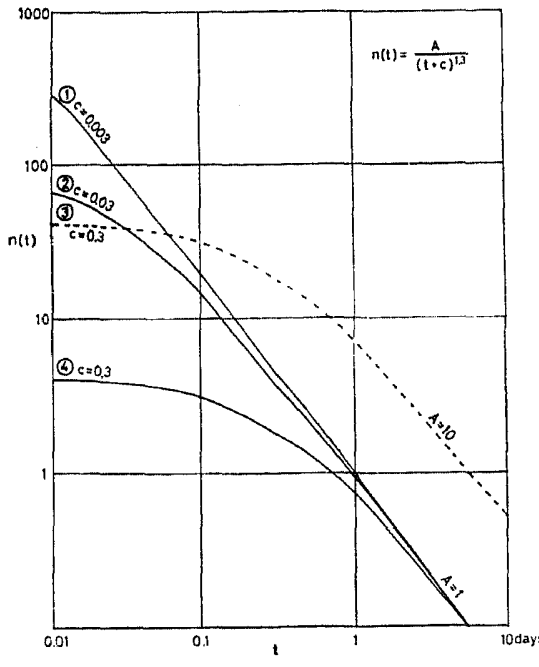

Fig. 8.

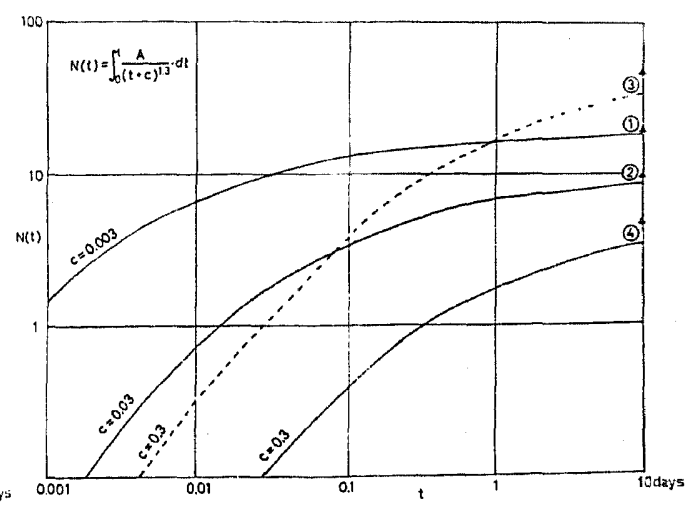

Fig. 9.

Figs. 8 and 9. The graphs of $n(t)$ and $N(t)$ for various values of $c$. Triangle represents the limit as $t \rightarrow \infty$. 


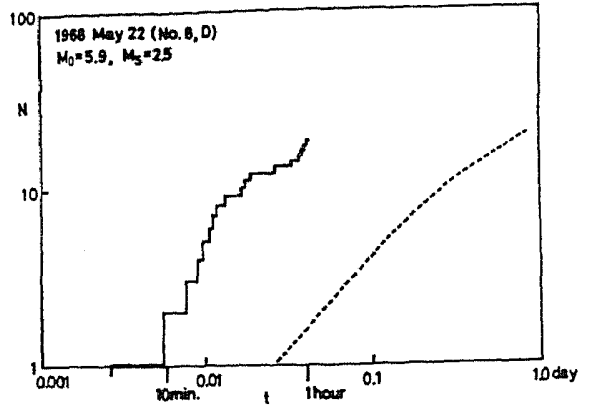

Fig. 10.

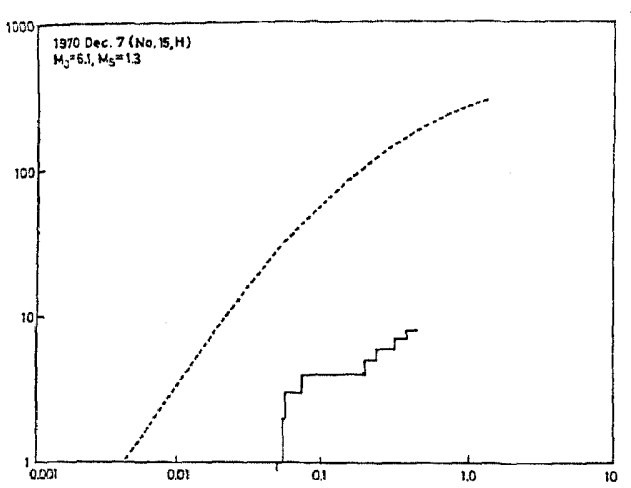

Fig. 12.

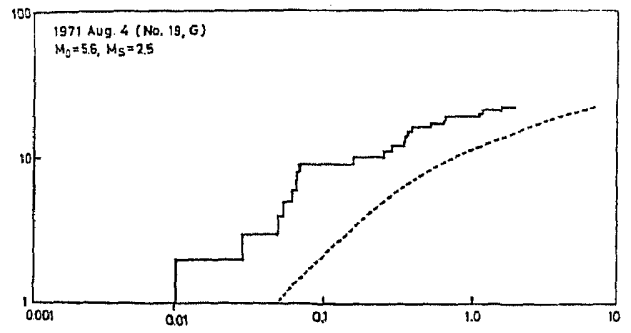

Fig. 14.

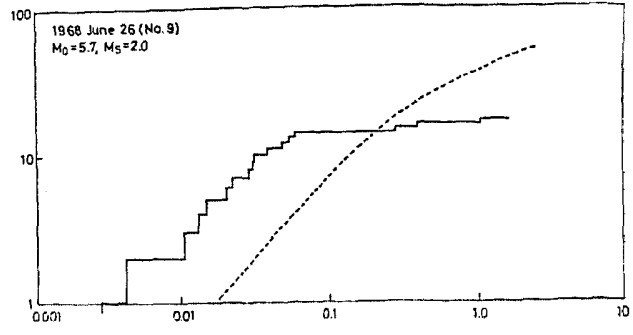

Fig. 11.

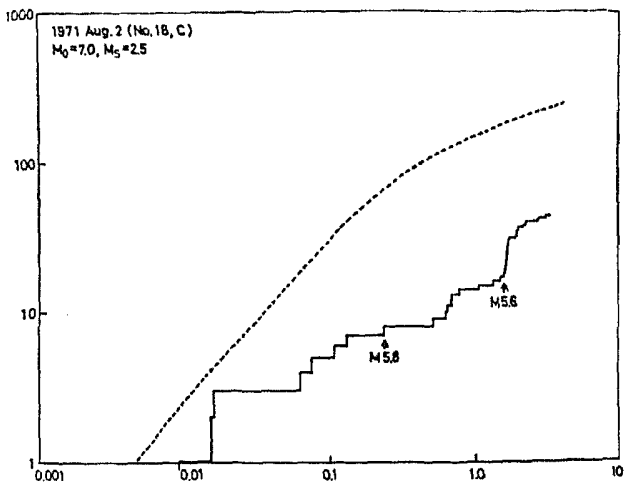

Fig. 13.

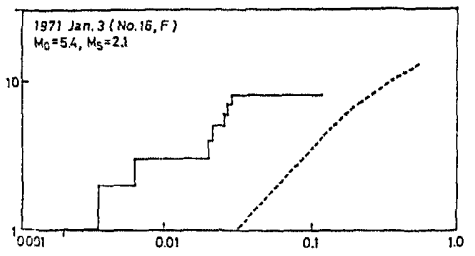

Fig. 15.

Figs. 10 to 15 . Cumulative frequency of aftershocks.

As described qualitatively in a previous section, it is clearly shown in Figs. 7 and 13 that the aftershock activity for the Erimomisaki-oki earthquake (C in Fig. 5) was very low. On the other hand, even if eventually we regard the second largest aftershock ( $G$ in Fig. 5) in this sequence as an independent main shock, Figure 14 shows that its aftershock activity raised to a standard level at least. It may be considered that aftershocks of an aftershock were 
not rare in this case. Moreover, an earthquake (F in Fig. 5), which occurred near the focal region of the Erimomisaki-oki earthquake a half year before its occurrence, it was also accompanied by many aftershocks as shown in Fig. 15 .

Using the method described above, we investigated all earthquakes (focal depth $\leqq 100 \mathrm{~km}$ ) of magnitude 5.5 and over located within the area shown in Fig. 16 from July 1967 to June 1972. Some of these shocks are aftershocks of the 1968 Tokachi-oki earthquake. In fact, the data on earthquakes on May 16 and 17, 1968 were not available due to overlapping of numerous aftershocks of this great earthquake. Figure 16 shows that aftershock activity for earthquakes occurring in the area of the 1968 Tokachi-oki earthquake is not always low. Mogr (1967 b) investigated regional variation of aftershock activity in and around Japan with its relation to mechanical structure of the earth's crust. However, our results indicate that aftershock activity may differ considerably from place to place in a limited region.

In general, the phenomena of secondary aftershocks may often be observed and their activities seem to be similar to primary aftershock activities in most cases. For example, most of major earthquakes occurred recently off the Pacific coast of Hokkaido and in the southern Kuril Islands region were accompanied by secondary aftershocks. These shocks are denoted by mark $\mathbf{S}$ in Table 4. Both the southern Kuril Island earthquake of $1963\left(M_{0}=8.1\right.$, $\left.M_{1}=6.7\right)$ and the Nemuro-oki earthquake of $1973\left(M_{0}=7.4, M_{1}=7.1\right)$ have also remarkable secondary aftershock sequences. The largest aftershock trig-

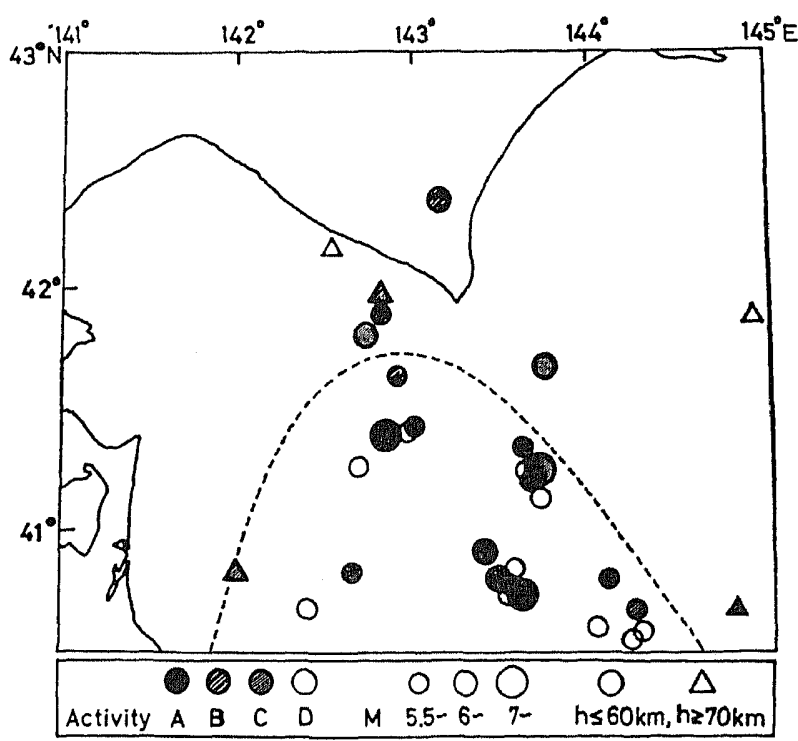

Fig. 16. Aftershock activity based on the number of aftershocks observed. 
gered its own aftershock activity for these cases, excepting the Erimomisakioki sequence in which not the largest aftershock but the second largest one was followed by the secondary events.

\subsection{Repeated aftershock activity in a limited region}

The aftershock sequence of the earthquake of July 1, 1970, magnitude of 5.1, was traced for four days after its occurrence as shown in Fig. 17. The activity was normal during this period. After that period, aftershocks were not distinguishable by the data obtained at KMU only. However, up to the end of 1972, five shocks in Table 6 were located by JMA within the small region shown in Fig. 18 and at the time of their occurrence the number of small earthquakes with nearly the same P-S intervals at KMU showed a sudden increase. It is almost impossible from Fig. 17 to regard all these shocks as aftershocks of the main shock of July 1, 1970, so far as we assume the standard rate of the occurrence of aftershocks. Moreover, time distribution of these small shocks is characterized by so-called "main shock-aftershock" pattern. So we would prefer considering that aftershock activity might occur repeatedly in a narrow region around the first main shock.

Table 6. Data on repeated aftershock activities in a limited region.

\begin{tabular}{crccccccc}
\hline Date & \multicolumn{1}{c}{ Long. } & Lat. & Depth & $M_{0}$ & $M_{1}$ & $M_{0}-M_{1}$ & Remarks \\
\hline 1970 July & 1 & $142^{\circ} 42^{\prime} \mathrm{E}$ & $41^{\circ} 33^{\prime} \mathrm{N}$ & $40 \mathrm{~km}$ & 5.1 & 5.1 & 0.0 & \\
July & 2 & $142^{\circ} 41^{\prime} \mathrm{E}$ & $41^{\circ} 36^{\prime} \mathrm{N}$ & 40 & 5.1 & & & aftershock \\
July & 3 & $142^{\circ} 44^{\prime} \mathrm{E}$ & $41^{\circ} 36^{\prime} \mathrm{N}$ & 50 & 4.2 & & & aftershock \\
July 23 & $142^{\circ} 43^{\prime} \mathrm{E}$ & $41^{\circ} 35^{\prime} \mathrm{N}$ & 40 & 4.5 & & & aftershock? \\
Aug. 20 & $142^{\circ} 43^{\prime} \mathrm{E}$ & $41^{\circ} 32^{\prime} \mathrm{N}$ & 30 & 4.5 & 4.0 & 0.5 & \\
Dec. 20 & $142^{\circ} 41^{\prime} \mathrm{E}$ & $41^{\circ} 31^{\prime} \mathrm{N}$ & 10 & 4.1 & 2.2 & 1.9 & \\
1971 Jan. 18 & $142^{\circ} 43^{\prime} \mathrm{E}$ & $41^{\circ} 33^{\prime} \mathrm{N}$ & 50 & 5.4 & 3.8 & 1.6 & \\
July 15 & $142^{\circ} 42^{\prime} \mathrm{E}$ & $41^{\circ} 33^{\prime} \mathrm{N}$ & 30 & 3.9 & & & foreshock \\
July 15 & $142^{\circ} 42^{\prime} \mathrm{E}$ & $41^{\circ} 34^{\prime} \mathrm{N}$ & 40 & 4.5 & 2.3 & 2.2 & \\
\hline
\end{tabular}

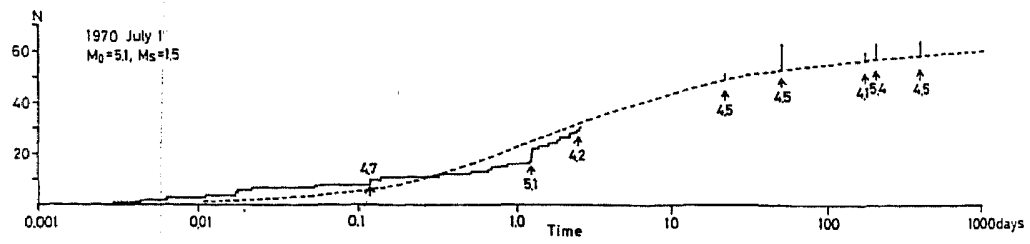

Fig. 17. Cumulative frequency of aftershocks plotted against the time from the main shock of July 1,1970 . Solid and dotted line indicate the observed and the calculated number of aftershocks, respectively. Bars indicate other main shocks. 


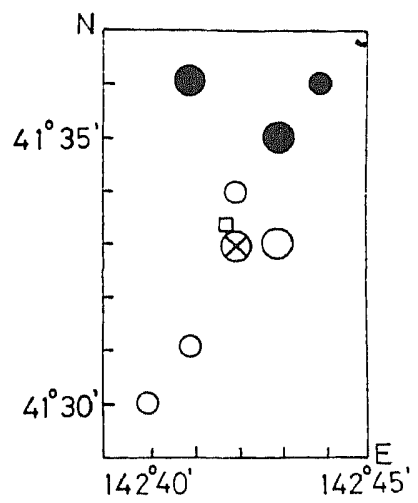

Fig. 18. Epicenters of earthquakes with special relation to aftershock sequence (after JMA).

$\otimes$; the first main shock

; aftershock of the first main shock

O; other main shock

$\square$; foreshock of the last main shock

\section{Concluding Remarks}

Some aftershock sequences were investigated using the data from the routine seismic observation at KMU. In a limited area some earthquakes have aftershocks and some ones, though with large magnitude, have no aftershock. So far many studies on aftershocks have been made on the basis of the data obtained in relatively late stages of the sequences. In this study, however, the data within one day after the main shock were investigated and some features of aftershocks in the early stages of the sequence were described. We found many sequences with very small $c$ value.

There has been an opinion that aftershocks of an aftershock are rare, but many secondary aftershock sequences may be found if we observe very small shocks. The Erimomisaki-oki earthquake is a good example of this concept. It was obviously accompanied by small secondary aftershocks which escaped from observation of JMA. A model was proposed by UTSU (1970) to explain the variety of temporal types of earthquake sequences in which the concept of trigger events and secondary aftershocks plays an important role.

The author is indebted to Professor Tokuji Utsu who read the manuscript critically. He also wishes to express his thanks to Professor Izumi Yokoyama and many colleagues at the Department of Geophysics, Faculty of Science, Hokkaido University for kind help in making the pre-KMU observation. Gratitude is expressed to the staff of Urakawa Seismological Observatory, Hokkaido University for the seismograms used. 


\section{REFERENCES}

Hrrota, T., Aftershock sequence of the earthquake off Shikotan Island on January 29, 1968, Geophys. Bull. Hokkaido Univ., 21, 33-43, 1969 a.

Hirota, T., Seismic activity in the Teshikaga region, Hokkaido (1926-1968), Geophys. Bull. Hokkaido Univ., 22, 49-72, 1969 b.

Kishio, M., H. Mochizuki, and M. Katsumata, A study of magnitude determination for deep earthquakes, Spring Autumnal Meeting Seismol. Soc. Japan, 31, 1972.

MoGr, K., Some discussions on aftershocks, foreshocks and earthquake swarms-the frature of a semi-infinite body caused by an inner stress origin and its relation to the earthquake phenomena (third paper), Bull. Earthq. Res. Inst., 41, 615-658, 1963.

MoGr, K., Foreshocks and earthquake sarwms, J. Seismol. Soc. Japan, (ii), 20, 143-146, 1967 a.

MoGI, K., Regional variation of aftershock activity, Bull. Earthq. Res. Inst., 45, 711-726, 1967 b.

MotoYA, Y., Y. YoNETA, and Y. SASAKI, Observation of microearthquakes in Hidaka district, southern Hokkaido-1964-, Geophys. Bull. Hokkaido Univ., 14, 73-80, 1965.

МоточA, Y., Observation of microearthquakes in Hidaka district, southern Hokkaido-1965-, Geophys. Bull. Hokkaido Univ., 18, 45-52, 1967.

MоточA, Y., Earthquake observations at the Urakawa Seismological Observatory (I), Geophys. Bull. Hokkaido Univ., 22, 39-48, 1969.

MотоY A, Y., Aftershock sequences recorded during a microearthquake observation in Hidaka district, Hokkaido (1964-1966), Geophys. Bull. Hokkaido Univ., 23, 29-47, 1970 a.

MотоуA, Y., Aftershock sequence of the earthquake east off Hokkaido on August 12, 1969, Geophys. Bull. Hokkaido Univ., 24, 93-106, 1970 b.

Motoya, Y. and M. Kitagamae, Report on the earthquake of southern part of Hokkaido on January 21, 1970, Geophys. Bull. Hokkaido Univ., 25, 140-153, 1971.

MotoyA, Y., Seismicity near Urakawa, Hokkaido (1967-1970), J. Seismol. Soc. Japan, (ii), 25, 83-91, 1972.

MotoyA, Y., Seismicity near the Urakawa Seismological Observatory, Abstracts, Spring Meeting Seismol. Soc. Japan, 4, 1973.

OKADA, H. and Y. MOTOYA, Aftershock sequence of the Tokachi-oki earthquake of 1968 , Geophys. Bull. Hokkaido Univ., 24, 141-165, 1970.

OKANO, K., Aftershock activity in the vicinity of Kyoto, Bull. Dis. Prev. Inst., 20, 17-22, 1970.

SuYehiro, S., T. ASADA, and M. OHTAKE, Foreshocks and aftershocks accompanying a perceptible earthquake in central Japan, Pap. Met. Geophys., 15, 71-88, 1964.

TsuBoi, C., Determination of GUTENBERG-RICHTER's magnitude of earthquakes occurring in and near Japan, J. Seismol. Soc. Japan, (ii), 7, 185-193, 1954.

UTsu, T., A statistical study on the occurrence of aftershocks, Geophys. Mag., 30, 521-605, 1961.

Utsu, T., Aftershock and earthquake statistics (I)-some parameters which characterize an aftershock sequence and their interrelations-, J. Fac. Sci. Hokkaido Univ., Ser. VII, 3, 129-195, 1969.

UTsU, T., Aftershock and earthquake statistics (II) - further investigation of aftershocks and other earthquake sequences based on a new classification of earthquake sequences-, $J$. Fac. Sci. Hokkaido Univ., Ser. VII, 3, 197-266, 1970. 